\title{
La noción de la realidad humana en Zubiri
}

\section{The notion of human reality in Zubiri}

\section{Referencia del ensayo}

\author{
- Francisco José Ureta Morales \\ - Universidad Rafael Landívar de Guatemala \\ fureta@psicousac.edu.gt
}

Ureta, F. (2020). La noción de la realidad humana en Zubiri. Revista Guatemalteca de Educación Superior, 3(1), 96-115. DOI: https://doi.org/10.46954/revistages.v111.8

\author{
Recibido 10/05/2020. \\ Revisado 12/05/2020. \\ Aceptado 21/06/2020.
}

\section{Resumen}

Este ensayo aborda la conformación y diversos aspectos de la noción de la realidad humana planteada por Zubiri. El desarrollo de su antropología filosófica partió de la fenomenología y permitió fundamentar el concepto del hombre, cómo se constituyó como tal y la forma en que enfrenta la realidad humana. El segundo componente del estudio lo conforma la realidad humana, la cual se basa en tres sistemas de notas: el de la vida, la realidad animada y el de la inteligencia sentiente. Esta última realiza la aprehensión y actualización de las cosas reales, la intelección. La realidad humana no concluye en el sistema de notas; se inserta en el mundo y es actual, por lo que el ser humano se desarrolla influenciado por la realidad donde se ubica. La evolución del organismo humano permitió la evolución de los procesos intelectivos de la inteligencia sentiente, de cómo se fue enfrentando a los objetos reales. Finalmente se analizó la fundamentalidad de lo real; las personas se fundan en la realidad, que es el poder de lo real. La realidad humana es inquieta, problemática, enigmática y se va descubriendo poco a poco. Se analizan las dimensiones del hombre, social, histórica, 
moral y de religación. Se concluye que la realidad humana planteada por Zubiri es una unidad radical de cuerpo y psique, se constituye por un sistema de notas integrado. La inteligencia sentiente le permite reflexionar sobre la realidad y su propia realidad.

\section{Abstract}

This essay deals with the shaping and various aspects of the notion of human reality put forward by Zubiri. The development of his philosophical anthropology started from phenomenology and allowed to base the concept of man, how he was constituted as such and the way he faces human reality. The second component of the study is made up of human reality, which is based on three systems of notes, that of life, animated reality, and that of sentient intelligence. The latter realizes the apprehension and actualization of real things, the intellection. Human reality does not end in the note system, it is inserted into the world and it is current, so that the human being develops influenced by the reality where he is located. The evolution of the human organism allowed the evolution of the intellective processes of the sentient intelligence, of how it faced the real objects confronted. Finally, the fundamentality of the real was analyzed, people are founded on reality, which is the power of the real. Human reality is restless, problematic, enigmatic and it is gradually being discovered. The dimensions of man, social, historical, moral and religious, are analyzed. It is concluded that the human reality proposed by Zubiri is a radical unity of body and psyche, it is constituted by an integrated system of notes, sentient intelligence allows him to reflect on reality and his own reality.

\section{Introducción}

¿Qué es el Hombre?, ¿qué diferencia sustancialmente al hombre de los animales?, ¿cómo se es hombre? y ¿qué dimensiones posee la realidad humana?; son algunas preguntas que el ser humano ha tratado de responder durante siglos. Las diversas respuestas y teorías desarrolladas condujeron a crear una disciplina específica, la antropología filosófica. Xavier Zubiri plantea un esquema de reflexión en esta línea, proponiendo la

\section{Palabras clave}

Realidad humana, inteligencia, inteligencia sentiente, esencias

\section{Keywords}

Human reality, intelligence, sentient intelligence, essences 
noción de realidad humana. Aspecto sobre el que sustenta su antropología filosófica, tarea a la que dedicó gran parte de su vida y sus escritos.

La realidad humana es la preocupación primordial de las siguientes páginas, desde su fundamento metafísico hasta la unidad psico-orgánica del hombre, analizando las diversas facetas intermedias. Finalmente, se discutirán los aportes de este esquema zubiriano a las ciencias sociales, por ser el estudio sistemático desde sus diversas facetas, donde podrían encontrar un soporte filosófico coherente, que tanta falta les ha hecho.

\section{Realidades y esencias}

Durante el presente ensayo de antropología filosófica, se abarcará el análisis de las realidades y esencias, la realidad humana, la fundamentalidad de lo real y las dimensiones del hombre desde la propuesta de Xavier Zubiri. La realidad y las cosas reales están constituidas por notas, las cuales son formas de la realidad, pertenecen a los objetos y los definen. Son notas de los objetos que notifican de su presencia y existencia; no se aprehenden los objetos sino sus notas. Al formar parte de los objetos se organizan en una unidad intrínseca como sistema cíclico. "La realidad se actualiza como un todo de notas, como una totalidad." (Gómez, 2014, p. 348).

Los objetos poseen dos tipos de notas constitucionales: el primero es adventicias, donde unas actúan sobre las otras; el segundo son las formales, que pertenecen a las cosas ya de suyo y no aceptan influencias de las otras notas. El sistema de notas que conforma un objeto posee autonomía y suficiencia en su constitución, de tal manera que se convierte en el modo que esa cosa es única, formando la sustantividad de los objetos. Las notas constitutivas de los objetos están fundadas en sí mismas, componen la esencia del subsistema radical de la sustantividad; son su principio estructural, las más propias y por ello diferencian estructuralmente a los objetos unos de otros. Se entiende como la nota en su carácter de ratificación, es decir, es la verdad real de la nota misma la que se impone físicamente, un pensador o investigador mienta la nota qua nota. Es su verdad física y real, 
que se impone estando presente desde sí, es el estando actual. (Espinoza, 2001).

Estos sistemas de notas se insertan y pertenecen de un modo propio a la realidad, son formas de la realidad. El momento en que se da la realidad es un momento abierto a todo, es la apertura de lo real hacia otros objetos y cosas reales, constituyendo el momento físico de la comunicación. La unidad respectiva de todas las realidades, tanto las conocidas como las desconocidas, se denomina mundo. El cosmos se define como la unidad y respectividad de las realidades ya constituidas; por diversa que sea, es realidad única en sí misma. Cada cosa real está presente en el mundo, este estar presente se le denomina actualidad. La realidad da origen al ser de las cosas, ya que el ser es siempre de la realidad y las cosas reales. La actualidad de lo real en el mundo es el ser, estar presente en el mundo en cuanto que estar.

\section{Realidad humana}

La realidad humana está constituida por tres grupos o sistemas de notas. El primer sistema de notas es el de la vida, se vive por y para ser sí mismo, posee cierta independencia y control sobre el medio. El segundo sistema se refiere a que es una realidad animada; es un animal que siente, tiene impresiones que lo afectan como viviente y que lo remiten a algo y otros que son diferentes de él y de sí mismo. El tercer grupo hace referencia a que el hombre tiene una inteligencia por la cual aprehende las cosas como reales, según como son las cosas de suyo. Es la facultad de lo real, capacidad de sentir la realidad por lo que es una intelección sentiente; es la que realiza la aprehensión de la realidad como formalidad de las cosas. La intelección es aprehensión de algo como real, por lo que la aprehensión primordial, como logos y razón, son ambos intelección, ya que ambos aprehenden lo real como realidad. La aprehensión es el acto que presenta las cosas y es consciente; entonces, la tarea de inteligir algo es, en efecto, aprehender intelectivamente este algo. La aprehensión logra la actualización de lo real en todas sus dimensiones, en la inteligencia sentiente del ser humano (Zorroza, 2015; Muñoz, 2005; López, 2013). 
El sistema de la sustantividad humana lo constituye la unidad radical de los tres grupos de notas, las cuales no se dan por aparte sino las tres constituidas interna y radicalmente en el hombre. Este sistema sustantivo tiene dos subsistemas: el primero es el cuerpo, son las notas físico-químicas interdependientes que materializan y expresan la actualidad del hombre en el universo. Lo rige el principio de actualidad, que es la unidad intrínseca de sus momentos: organismo, solidaridad y actualidad. El segundo subsistema es la psique. La psique de un organismo es orgánica y unida al cuerpo indisolublemente. Unidos ambos sistemas conforman lo psicorgánico y toman sustantividad en el sistema, en el organismo.

Ambos se codeterminan en todos los actos humanos, lo orgánico es psíquico y lo psíquico es orgánico. Las notas humanas se dan en una unidad coherente que permite la unidad del sentir humano en sus tres momentos de receptor, tónico y efector; se siente él mismo y siente la realidad. Aunado a todo este sistema de notas humanas, Zubiri define así al hombre:

"Por tanto el hombre es un animal que se enfrenta con la realidad: es un animal de realidades. He aquí la esencia de la realidad humana, la esencia de la sustantividad humana. El ámbito constitutivo del hombre es realidad: estamos en la realidad. Desde el punto de vista de sus notas, esto es, desde el punto de vista talitativo, el hombre es animal de realidades." (Zubiri, 1988, p. 46).

Sin embargo, la realidad humana no se agota en el sistema de notas, sino que se implanta en el mundo y es actual. De tal manera que se desarrolla el ser humano influenciado por esa realidad donde se ubica, así como la actualización que hace de ella dentro de sí.

La realidad humana también posee un ser, entendida como la actualidad de lo real en el mundo, que es la actualización en el mundo de la sustantividad personal, la persona como el modo de realidad relativamente absoluta. El yo es la entidad que permite realizar la actualidad de la persona en el mundo, es el ser de la persona. Por eso puede afirmarse que soy mío en cuanto ser, el 
cual es mi sustantividad personal; pero lo primario no es el yo, sino la realidad en cuanto tal. El yo está puesto en la realidad, mi realidad sustantiva es la que pone la actualidad mundanal de mi persona.

Existe también unidad entre el ser y la realidad humana, al yo no le es ajena dicha realidad. La realidad humana siendo se constituye con el hombre siendo yo. La parte absoluta del hombre se enfrenta a otros absolutos, juntos forman la especie humana como concepto que pertenece a cada animal humano, lo pluraliza o multiplica de una forma que lo constituye. El hombre como animal personal permite que mi realidad se vierta en la de otras personas, y mi realidad esquemática, en consecuencia, está afectada por la de otras personas. Las personas se codeterminan en la unidad de su sistema, la diversidad es la distinción dentro de la misma especie. Yo soy absoluto diversamente, yo estoy codeterminado por un tú y un él, da origen a la sociedad humana, que es la convivencia de un hombre con los demás hombres en tanto que realidades.

Hay que profundizar más el análisis sobre el cuerpo y la psique del hombre; pero considerando su evolución y origen sobre la tierra, esta perspectiva evolutiva ofrece nuevos horizontes. Innegablemente existe una evolución morfológica que colocó al hombre en la línea de los primates antropomorfos, en la bifurcación entre los póngidos y los homínidos. Esta evolución somática necesita tomar en cuenta otro aspecto: que el hombre posee una esencial irreductibilidad de su dimensión intelectiva a solamente dimensiones sensitivas animales; ellos reaccionan solamente ante estímulos. El phylum está constituido por una inteligencia, que ha evolucionado junto a las estructuras somáticas, no generando hombres distintos, sino tipos de vida estructuralmente distintos. En los cuatro tipos de hombres que se conocen, los hominizados (australopitecos $u$ homo habilis), arcantropos, paleantropos o los neantropos, no están claramente estratificados, sino que se superponen a veces por mucho tiempo. Esta sucesión de tipos humanos es una verdadera evolución genética, ya que la morfología comparada entre ellos y la flora y fauna que los rodeó así lo sugiere, confirmado por la continuidad evolutiva de las industrias que manejaron. El hombre no es una única realidad, son realidades los distintos tipos evolutivos descubiertos. 
Todos estos tipos humanos son formalmente hombres, ya que con su inteligencia (pobre o desarrollada) hicieron una cultura creadora. Fueron evolucionando lenta y progresivamente durante miles de años, desde sus niveles de animales inteligentes hasta los niveles de animales racionales, cuya plenitud es el homo sapiens. Así lo indica Zubiri:

"Los tipos hominizados anteriores al homo sapiens serían como esbozos progresivos, orientados evolutivamente a la constitución del homo sapiens, del animal racional. Es la evolución no de lo infrahumano a lo humano, sino la evolución humana de la inteligencia a la razón. El homo sapiens no constituye una excepción en la historia evolutiva de la humanidad, sino que hacia él va dirigida ésta." (Zubiri, 1982, p. 42).

La evolución es la transformación somática y psíquica de los tipos humanos, unidad sustancial de la realidad humana, aspectos que ahora serán analizados más profundamente. El cuerpo humano como realidad está compuesto de notas, en este caso, de notas físico-químicas. La sustantividad del cuerpo está compuesta por el sistema de notas constitutivas, clausurado y cíclico. Cada nota es solidaria con todas las demás; esta solidaridad es un momento formal del sistema sustantivo, basado en la organización, pero diferente de ésta. Esta sustantividad del cuerpo es psicoorgánica, debido a su radical unión entre el cuerpo y la psique, característica de la realidad humana. Por ello posee un momento de corporeidad, de presencia física en la realidad. El organismo tiene una función somática, es el fundamento material de la actualidad presencial. La evolución somática del cuerpo le ha permitido al hombre enfrentarse de mejor manera a la realidad y a las cosas reales, sin olvidar que al mismo tiempo influenció a la psique, aspecto que será tratado a continuación.

Desde sus orígenes el hombre se ha tenido que enfrentar con las cosas reales, las cuales no solo tienen que existir, sino que estén presentes ante nosotros. La forma en que las cosas se presentan ante nosotros es a través de los sentidos; lo sensible es la primera vía de acceso a la realidad. Los objetos afectan físicamente a los sentidos, sentir es formalmente intuir las cosas, lo sensible de la intuición es la impresión física en los sentidos. Estos 
brindan impresiones de las cualidades de los objetos, este contenido perceptivo expresa a las cosas siendo, momento o formalidad de lo real. En un sentido radical, la corporeidad no es una cosa o algo que meramente esté allí y pueda ser objetivado, el cuerpo acontece y se estructura en la acción plenaria del sentir la realidad mundanal que nos rodea. En la actualización corpórea de la realidad humana se realiza la estructuración de la unidad psico-orgánica y del aparecer de las cosas en el campo de realidad; lo entiende como el modo radical de aprehensión de lo real y permite que estemos retenidos en la realidad, la aprehensión primordial de realidad. (García, 2012; García, 2014).

La aprehensión de la realidad es el acto elemental de la inteligencia humana, hecha por los actos intelectuales que se mueven aprehendiendo las cosas como realidades. El sentir es la estimulidad de la formalidad de las cosas para responder ante ellas, la intelección se dirige a la realidad de la formalidad según las cosas son de suyo. La inteligencia está en continuidad con el sentir, pero las cosas la fuerzan a hacerse cargo de la realidad como primer acto psicobiológico del desarrollo intelectivo. La investigación fundamenta la inteligencia sentiente y a la realidad, la cual da de sí indicando al investigador que va en la vía apropiada (Muñoz, 2009). Por ello, Zubiri propone que la estructura esencial de la inteligencia se caracteriza por ser una inteligencia sentiente, ya que accede a la realidad sensible en forma de impresión, es un intelegir sentiente.

"La unidad de sensibilidad e inteligencia no está constituida, pues, por la unidad del objeto conocido, sino que es algo más hondo y radical: es la unidad del acto aprehensor mismo de la realidad como formalidad de las cosas. Trátase pues, de un solo acto en cuanto acto. Es lo que significa la expresión "inteligencia sentiente"." (Zubiri, 1982, p. 113).

Al evolucionar el organismo evolucionó también la psique humana, especialmente en lo concerniente a los procesos intelectivos de la inteligencia sentiente, cómo el hombre fue enfrentándose de diferente manera a los objetos reales, tal como se observa en las evidencias arqueológicas y antropológicas recientemente descubiertas. Su función es aprehender las 
cosas como reales, en su formalidad de realidad rigurosamente sentida, el hombre siente la formalidad de lo real, por lo que se afirma que la inteligencia es sentiente y no sensible. (García, 2006).

Analizados los aspectos metafísico y evolutivo de la realidad humana, ahora se analizará la génesis y constitución de dicha realidad. Tal como se indicó con anterioridad, la realidad humana es un sistema de notas constitutivas, físico-químicas y psíquicas que se influyen mutuamente en la actividad unitaria del hombre. En la célula germinal está presente lo psíquico y lo somático, pero lo psíquico está pasivo, las acciones físico-químicas son en ese momento las que predominan y modelan lo psíquico, formándose las estructuras y el soma donde se desarrolla lo psíquico. En la vida adulta sucede lo contrario, lo psíquico llega a predominar sobre el soma, pero siempre el sistema de notas entero está en actividad.

Zubiri sugiere que la génesis de la realidad humana se produce en el momento de la concepción, ya que la célula germinal está completa y empieza a enfrentarse o hacerse cargo de la realidad. El primer momento estructural esencial es la unidad hiperformalización-inconclusión, las células humanas que parten de la germinal y se van formalizando en sus funciones, por supuesto las neuronas son las hiperformalizadas. La inconclusión es más relacionada a lo psíquico y se refiere a las respuestas no conclusas del hombre, a la posibilidad de escoger y optar por diferentes respuestas en orden a la acción por ejecutar. Como la unidad de estos dos aspectos está presente desde la célula germinal, esta se constituye en la génesis de la realidad humana.

La actividad humana posee una estructura que favorece un funcionamiento de pasividad-actividad, tal como se explicó en las líneas anteriores. Entre estos polos se dan variaciones de uno hasta llegar al otro entre las notas psíquicas y físico-químicas. Existen dominancias de una hacia la otra, así es como transcurre genética, gradual y estructuralmente el carácter propio de la actividad psico-orgánica. Como conclusión del análisis de este aspecto, se dice que las opciones de acción que tiene el hombre son un acto de voluntad, son preferencia por ciertos actos, como determinaciones tomadas se incorporan a nuestra realidad, es un 
acto volitivo-cerebral. La voluntad es la organización preferencial de los impulsos, posible por el carácter inconcluso de estos, acción que transcurre en el cerebro; así actúa integralmente el sistema sustantivo psico-orgánico. La actividad humana como se ha descrito, es la que constituye a la realidad humana como tal.

La vida, como concepto de Zubiri, es el conjunto de lo que el hombre hace, cuya unidad interna está basada en el viviente mismo, de quien es la vida, el hombre. La realidad humana es la vida, vivida de manera espontánea y con carácter vivencial, constituida por el carácter esencial de una acción vital; la vivencia referida a la realidad sólo puede ser mía, personal. Vivir es estar en acción como sustantividad (unidad radical de las notas humanas), este movimiento reconforma mi propia sustantividad, la cual se va afirmando de distintas formas, por lo que vivir es poseerse en tanto que pura sustantividad. Por lo que Zubiri afirma:

"La vida se despliega en una tensión dinámica. Afirmar su propia sustantividad poseída en esa tensión dinámica, he ahí formalmente el carácter de la vida humana. En esa tensión, la vida se despliega en una sola estructura con tres fases cualitativamente distintas: el hombre nace, discurre por la vida y muere a la vida." (Zubiri, 1986, p. 554).

Sin embargo, la vida no es algo en sí sustantivo, sino que es un modo fundamental del viviente, por lo que no puede separarse de éste en su análisis, siempre está referida al hombre. La primera fase de la vida es el nacimiento, donde los padres realizan la transmisión de las estructuras somáticas. Está constituida a su vez, de tres fases; es la constitución de una sustantividad viviente independiente y única, posee una estructura de vida que le lleva al mundo y, es la apertura a ese mundo. La segunda fase es el decurso vital, son estados superiores de vida que se basan en los inferiores, hay independencia del medio y control sobre él. Luego el niño aprende a percibir, moverse y orientar el empuje vital en impulsos, estos tres aspectos operan juntos en la educación. Empieza a hacerse cargo de las situaciones para dar respuestas adecuadas, clave de lo que es la vida humana; enfrentarse con las cosas y habérselas con ellas como realidades, ambos actos 
son las dimensiones radicales de la vida del hombre. En esta etapa vivir es poseerse en forma satisfactoria, esto implica no solo ejecución sino una confirmación de sí mismo.

La autoposesión posee tres dimensiones de ejecución (agente), decisión (autor) y aceptación (actor de la vida), y expresan la sustantividad en su triple carácter. La estructura del decurso vital está formada de libertad, temporalidad y realización, su unidad radical es el todo de la vida decurrente. Es natural y libre al mismo tiempo, puedo tomar decisiones auténticas en lo más profundo de mi propia realidad. El hombre construye lo que va a elegir, esos proyectos remiten a la temporalidad, radicada en el carácter futuro del proyecto y la inteligencia sentiente es su fundamento último. En esta fase el hombre se muestra como una voluntad tendente, prefiere hacer ciertas cosas con lo que se va haciendo y cambiando a sí mismo, igual que como la realidad va cambiando.

La tercera y última fase es la muerte, se vive en un emplazamiento que consiste en tener que morir, dura mientras se vive y llega la muerte. Así como la vida es autodefinición de la figura que se quiere ser, una definición siempre abierta a cambios, la muerte es el momento en que esa figura deja de ser definitoria para ser definitiva, lanza al hombre de la provisionalidad a lo definitivo. La vivencia de la muerte se puede experimentar a lo largo de la vida, viendo morir a otros ayuda a aguardarla como parte de la vida misma. Es física, ya que destruye la configuración física de las moléculas del organismo, pero es un fenómeno psicofísico ya que el cuerpo se despide del psiquismo y se queda sin la vida, la sustantividad humana deja de existir.

\section{Fundamentalidad de lo real}

Ahora se analizará la fundamentalidad de lo real, ya que el hombre realiza acciones frente a las cosas y en la realidad, adquiere su carácter relativamente absoluto y se funda en ella. La persona está fundada en la realidad, es el apoyo de las acciones de mi persona, al decidir se opta por una posibilidad entre varias; la realidad es el apoyo impelente o sea que al accionar tiene que hacer la acción. Estos tres aspectos son la fundamentalidad de 
lo real, cuya estructura se basa en que la realidad es dominante, ejerce dominio, y nos hace ser realidades personales, el dominio es poder, la realidad es el poder de lo real.

El poder se apodera de lo dominado, el poder de lo real se apodera de mí, por ello me hago persona, la realidad funda una realidad personal por apoderamiento debido al poder de lo real. Esta es la fundamentalidad de mi realidad personal, ya que la realidad se apodera de mí y tiene muchas manifestaciones, compete a la realidad de las cosas reales. La fundamentalidad acontece al ligarse al poder de lo real, nos volvemos relativamente absolutos; esta es la religación de naturaleza constitutiva y formal, la cual es constatable, total y radical.

La religación es experiencia de la realidad como poder, es la probación física de la realidad de algo, se insertan las posibilidades de realización de las notas en la realización de mi persona. Se manifiesta en ella el poder de lo real, a través de las notas en que lo real se actualiza. Es enigmática ya que toda cosa real impone, por su constitución, que se adopte una forma determinada de realidad, significa lo real indicándolo significativamente, es estar en la realidad con las cosas reales. Debido a que el poder de lo real es enigmático, le imprime este carácter a la realización de nuestra realidad personal, esto es el problematismo de la fundamentalidad.

La realidad humana está inquieta porque busca la felicidad, el hombre es en sí mismo inquietud; ya que la realidad es enigmática origina la pregunta ¿qué voy a hacer de mí?, es la pregunta que da origen a la inquietud. El problematismo en cuestión posee varios momentos, el primero es que mi propia realidad es para mí algo enigmático, se va desarrollando y descubriendo poco a poco. El segundo momento emerge con la voz de la conciencia, sale del fondo de mí mismo y es el carácter absoluto de mi realidad, dicta una forma de realidad que he de adoptar. Como voz interna es una forma de intelección sentiente, es la voz del problematismo de lo real al cual nos lanza. El tercer momento es la volición, cuando se determina la realidad que se ha de adoptar, es también una volición sentiente con carácter de determinación tendente a una forma de realidad, a la cual estamos lanzados, es la voluntad de mi realidad personal. Se esfuerza por tener 
actualizada la realidad fundamentante, es la voluntad de verdad real, o sea, ser una realidad meramente actualizada en mi intelección. Así es, así será y está siendo, estos tres momentos de manifestación, fidelidad y efectividad se manifiestan en una unidad que constituye la verdad real.

Cuando el hombre adopta una forma de realidad esta es optativa, la voluntad de verdad se objetiva en una búsqueda, búsqueda de cómo se articulan las cosas reales en la realidad, para poder optar por una forma de realidad. Esta fundamentalidad o realidad-fundamento, fundamenta mi realidad personal en la realidad; esta experiencia de búsqueda de fundamento en la fundamentalidad del poder de lo real, la designa Zubiri como la experiencia teologal:

"Esta articulación es un momento de toda cosa real, es su momento de fundamentalidad, el cual por tanto constituye la fundamentalidad de mi realidad personal. Es un momento de fundamentalidad porque no es una realidad-objeto sino una realidad-fundamento. Es lo que buscamos. La realidad-fundamento es la solución del enigma de la realidad y de mi realidad personal." (Zubiri, 1988, p. 110).

\section{Las dimensiones del hombre}

El anterior análisis fundamental concluye la revisión de la realidad humana, pero ahora se abre hacia el análisis de las dimensiones del hombre. El hombre posee una dimensión social, se codeterminan unos a otros los seres humanos, es comunalmente absoluto, desde sí mismo hacia la convivencia con los demás. Se parte del elemento individual, como concreción de la persona por la individualidad de sus notas y del sistema sustantivo que a cada una constituye, su propia persona y respecto de otras personas. La realidad humana es social, se realiza ya que diversos seres individuales conviven en sociedad de hombres reales en cuanto que reales, como animal de realidades de una manera impersonal y en comunión. En continuidad con el pensamiento de Comte, indica que los seres humanos viven en cada instante en una unidad social, esta unidad es la que 
les da su última concreción, esta intersubjetividad radical se realiza en un equilibrio entre individuos (Zubiri, 1992; Antúnez, 2006). La especie humana es genéticamente prospectiva, cada uno determina la continuación de la especie, biogenética e históricamente, de aquí surge la siguiente dimensión.

La dimensión histórica del ser humano es de carácter prospectivo, ir hacia adelante. Esta dimensión le permite al hombre transmitir la vida y la tradición, como un sistema de posibilidades sociales para realizarse. La historia procede por invención ya que es una opción para estar en la realidad, por ello es de carácter optativo, procesual y genética. La historia es un proceso de sucesos, es una sucesión de los modos de estar en la realidad, se convierte en un proceso de posibilitación del hombre en la tradición (entregas de cómo estar en la realidad). El individuo histórico es el que está determinado por la historia, la dimensión histórica es una refluencia de la prospectividad esquemática de mi realidad sustantiva sobre esta misma realidad. Esta dimensión consiste en un proceso de capacitación y posibilitación, es un proceso de realización histórica de lo posible en cuanto tal, proceso de sucesos como actualización procesual de lo posible.

Cuando el hombre va haciendo su vida, elige unas cosas y rechaza otras, va determinando su figura en gran parte por las decisiones que se van tomando, se apropia de una o varias posibilidades, dando paso a la dimensión moral del hombre. Este justifica sus acciones al preferir una posibilidad entre otras también posibles, lo constituye en una realidad moral, fundando el bien y el mal. Lo moral es relativo a la apropiación de una posibilidad, se define por el modo de tener y apropiarse de la realidad. Por ello el hombre es también un animal de posibilidades apropiadas, animal moral, puede hacer su vida escogiendo entre las posibilidades que tiene a su alcance; por lo tanto, además puede ser un animal de ideales.

La felicidad humana es la posibilidad suprema entre todas las posibilidades, el hombre va a ser feliz en la medida que se apropia de sí mismo proyectado en su misma realidad, es su rigurosa apropiación. Así las cosas, el hombre se ubica también como un animal de bienes, cuyo bien radical y último es su propia felicidad; tiene por ello la posibilidad de estar suspenso 
entre la felicidad y la infelicidad. Origina la incertidumbre moral, ya que el hombre en su camino hacia la felicidad y perfección, posee una amplia gama de posibilidades que las convierten en cosas constitutivamente indeterminadas, así se afirma:

"La concreción de la moral es la apropiación racional y razonable de las posibilidades que van implicadas incoativamente en la idea del hombre, perfectamente actualizada en cada una de sus situaciones. Eso y no otra cosa es lo que constituye la felicidad del hombre. De esa felicidad penden los deberes, y la felicidad a su vez pende de la índole misma de una realidad: la realidad humana que está constitutivamente abierta a su interna justificación." (Zubiri, 1986, p. 440).

La moral interviene en el momento en que la inteligencia sentiente se hace cargo de la realidad, se apropia entonces de algunas posibilidades de realización humana. En anteriores páginas se analizó la fundamentalidad y el poder de lo real, y de cómo el hombre al religarse a ello, adquiere la fundamentalidad de su realidad personal, aquí surge la dimensión teologal del hombre. Gracias a la religación al poder de lo real el hombre puede realizarse con las cosas, con los demás y consigo mismo; la religación es una dimensión constitutiva de la persona humana, ya que está constitutivamente enfrentado con el poder de lo real. Al vivir problemáticamente el poder de lo real, se vive problemáticamente mi realidad relativamente absoluta, este problema del poder de lo real en mi religación es el problema de Dios. El hombre no tiene el problema de Dios, sino que al constituir su yo surge formalmente el problema de Dios, es por tanto un problema personal.

Zubiri plantea que Dios es el fundamento del poder de lo real, realidad suprema (última, posibilitante e impelente) que fundamenta mi relativo ser absoluto, por ello es absolutamente absoluto. Religarse al poder de lo real perfila una idea predeterminada de Dios, común a todos, presente en todas las culturas, sin importar cuál sea; originando la discusión y tanteo de la realidad o no realidad de esta realidad absolutamente absoluta. La dimensión teologal del hombre surge al plantearse la religación al poder de lo real, del cual Dios es el fundamento, fundamentando de una vez mi yo personal. 


\section{Conclusiones}

La realidad humana planteada por Zubiri constituye al hombre como una unidad radical entre cuerpo y psique, visión unitaria que supera la noción griega de mente y cuerpo; considerando los avances de algunas ciencias como la psicología, antropología, paleontología y biología principalmente. Utiliza conceptos provenientes de la teoría sistémica, ya que el hombre es un sistema de notas integrado, igual considera al mundo como un sistema de realidades, las cuales se autodeterminan aunque posean cierta independencia. En este sentido su propuesta es de carácter funcionalista, especialmente en el aspecto sistémico de las notas humanas y cómo se relacionan entre ellas. También, al suponer que el hombre se va haciendo con sus actos, abordando y poseyendo la realidad y su propia persona, acierta en el sentido de que el hombre es de una forma, pero tiene la libertad para ser de otra forma si así lo desea. La idea del hombre y la realidad como sistemas es apropiada para explicarlas, ambas se codeterminan e influyen, estableciendo una idea unitaria del hombre.

La noción planteada del ser humano como un animal de realidades en su estructura primaria y radical, sustantividad constituida por su inteligencia sentiente, ubica al hombre como el único ser capaz de reflexionar sobre la realidad y su propia realidad. La visión sostenida en el análisis previo de carácter genético y evolutivo, favorece la contemplación total de la realidad humana, desde su inicial formación y desarrollo como especie, así como realidad personal al constituirse desde la célula germinal. Esta capacidad reflexiva le permite ser una esencia abierta al orbe de la perfectividad, aprehende la realidad y haciéndolo la posee, siente inteligentemente la realidad a la que está enfrentado. Concepción que respeta la unidad del hombre en sus aspectos psíquico y orgánico, pero descuida la otra parte social; ya que la ubica como una dimensión del hombre, junto con la histórica, moral y teologal, que si bien es cierto lo constituyen él considera que no es parte de su sustantividad radical como en efecto es.

Todo su esquema de antropología filosófica se instala en una visión de idealismo realista, une conceptos ideales y reales sobre el hombre. La visión sistémica es funcionalista con 
características de idealismo, pero acepta la existencia de la realidad independiente de él a la cual se enfrenta y debe poseer. Ambas ideas no riñen entre sí, al contrario, logra amalgamarlas creando un sistema coherente consigo mismo.

En este acierto se encuentra presente su limitación, ya que como esquema filosófico solo puede ofrecer sustento a investigaciones sociales ubicadas en esta perspectiva. Su concepción como tal, a pesar de tener una visión unitaria del hombre, es un tanto parcial y limitada, características de los sistemas filosóficos que se han desarrollado, responden a ciertas preguntas, pero no a todas. Las ciencias sociales (sociología, psicología, antropología, arqueología, historia, etc.) pueden enriquecerse al fundamentar ciertos procesos investigativos sobre la concepción Zubiriana, explicando y describiendo principalmente cómo el hombre posee la y sus realidades. Lo cual es una parte del hombre, pero al intentar hacer correlaciones y predicciones sobre él, perspectivas científicas también (aunque ingenuas), este esquema Zubiriano no responde, ya que estos procedimientos también han permitido que el hombre reflexione sobre sí mismo.

Sin embargo, las pocas investigaciones sociales que se hacen en este país, aunque estén acordes al pensamiento Zubiriano sobre el hombre, muchas no incluyen dentro de sí su fundamento filosófico, error enorme en que se incurre muchas veces por desconocimiento. Crean investigaciones sin un marco filosófico coherente con ellas mismas; en consecuencia, la interpretación de los datos obtenidos que se hace, podrá tener respaldo empírico o experiencial pero no filosófico, que a la larga se constituye en su fundamento principal. Como ejemplo de esta situación, basta con hacer una revisión al tesario de las diferentes facultades que forman cientistas sociales, en la cual se observaría la falta de una fundamentación filosófica coherente de los trabajos realizados. Situación que podría cambiarse al fortalecer la formación de dichos profesionales en investigación social, desde su epistemología y antropología filosófica hasta el correcto diseño de instrumentos e interpretación de resultados. Para que concepciones humanas como la Zubiriana, se conozcan y puedan aplicarse en dichas investigaciones, creando estudios con un marco filosófico coherente. 


\section{Referencias bibliográficas}

Antúnez, J. (2006). La intersubjetividad en Xavier Zubiri. Editrice Pontificia Universit Gregoriana. https://philpapers.org/ archive/CIDLIE.pdf

Espinoza, R. (2001). El logos nominal constructo en el pensamiento de Zubiri. The Xavier Zubiri Review, 3, 121132. http://www.zubiri.org/general/xzreview/2000/web/ lolas2000.htm

García, J. (2006). Inteligencia sentiente, reidad, Dios. Nociones fundamentales en la filosofía de Zubiri. Cuadernos de pensamiento español. Servicio de publicaciones de la Universidad de Navarra, S. A. https://dadun.unav.edu/ bitstream/10171/7121/1/30.pdf

García, M. (2014). La idea de verdad desde la teoría de la inteligencia de Xavier Zubiri. Tesis de licenciatura. Universidad Centroamericana José Simeón Cañas. https:// www.academia.edu/9350415/La_idea_de_verdad_desde_ la_teor\%C3\%ADa_de_la_inteligencia_de_Xavier_Zubiri

García, M. (2012). Análisis metafísico-noológico de la corporeidad desde el pensamiento de Xavier Zubiri: la apertura corporal. Thémata. Revista de Filosofía. (46), 599-606. http://institucional.us.es/revistas/themata/46/art_57.pdf

Gómez, J. (2014). La realidad del sentido. El problema de la fundamentación de las interpretaciones desde Heidegger y Zubiri. Tesis doctoral. Universidad de Granada. https:// hera.ugr.es/tesisugr/23731862.pdf

López, J. (2013). Esencia y transcendentalidad en el realismo de Zubiri. Tesis doctoral. Universidad Nacional de Educación a Distancia (UNED). https://dialnet.unirioja.es/servlet/ tesis?codigo $=37730$ 
Muñoz, F. (2009). Realidad y verdad base metafísica y base noológica del inconformismo epistemológico de un investigador. Cuadernos salmantinos de filosofía, 36, 95-102. https://dialnet.unirioja.es/servlet/ articulo?codigo=3075227, https://doi.org/10.36576/ summa.29089

Muñoz, D. (2005). La esperanza humana como apertura a la transcendencia: una propuesta de inspiración Zubiriana. Extracto de tesis doctoral. Pontificia Universitas Mexicana. https://www.academia.edu/39399042/ PONTIFICIA_UNIVERSITAS_MEXICANA_Facultas_ Philosophiae_LA_ESPERANZA_HUMANA_COMO_ APERTURA_A_LA_TRANSCENDENCIA_UNA_ PROPUESTA_DE_INSPIRACI\%C3\%93N_ZUBIRIANA_ Auctore_Diego_Mu\%C3\%B10z_Ortiz_Excerpta_ex_ dissertatione_ad_Doctoratum

Zorroza, M. (2015). La prosecución realista del conocer humano: Xavier Zubiri y Leonardo Polo. Studia Poliana 17, 15-40. https://dadun.unav.edu/bitstream/10171/42953/1/02. pdf

Zubiri, X. (1992). Cinco lecciones de filosofía. (3a. ed.). Alianza Editorial.

Zubiri, X. (1988). El hombre y Dios. (4a. ed.). Alianza Editorial.

Zubiri, X. (1986). Sobre el hombre. Alianza Editorial.

Zubiri, X. (1982). Siete ensayos de antropología filosófica. Universidad Santo Tomás, Centro de enseñanza desescolarizada. 


\section{Sobre el autor}

Francisco José Ureta Morales es profesor universitario con licenciatura en psicología por la Universidad de San Carlos, maestrías en educación con especialidad en currículo y, en medición, evaluación e investigación educativas por la Universidad Del Valle de Guatemala, cierre de pensum del doctorado en filosofía por la Universidad Rafael Landívar. Con publicaciones sobre temas educativos y psicológicos en diversas revistas especializadas.

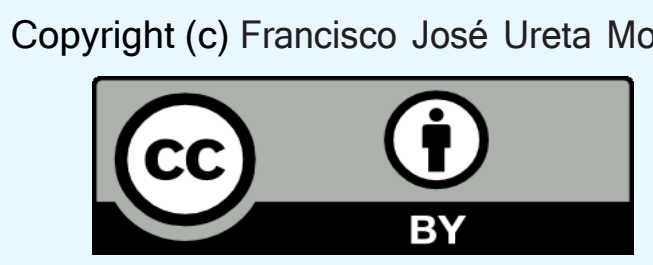

Este texto está protegido por una licencia CreativeCommons 4.0.

Usted es libre para compartir, copiar y redistribuir el material en cualquier medio o formato y adaptar el documento, remezclar, transformar y crear a partir del material para cualquier propósito, incluso comercialmente, siempre que cumpla la condición de atribución: usted debe reconocer el crédito de una obra de manera adecuada, proporcionar un enlace a la licencia, e indicar si se han realizado cambios. Puede hacerlo en cualquier forma razonable, pero no de forma tal que sugiera que tiene el apoyo del licenciante o lo recibe por el uso que hace. 